\title{
Effects of partial rootzone drying and rootstock vigour on growth and fruit quality of 'Pink Lady' apple trees in Mediterranean environments
}

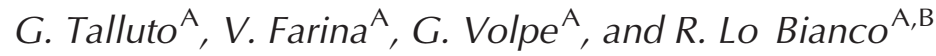 \\ A Dipartimento S.En.Fi.Mi.Zo., Sezione di Frutticoltura Mediterranea, Tropicale e Subtropicale, \\ Università degli Studi di Palermo, Viale delle Scienze 11, 90128 Palermo, Italy. \\ ${ }^{\mathrm{B} C}$ Corresponding author. Email: rlb@unipa.it
}

\begin{abstract}
We investigated the effects of partial rootzone drying (PRD) and rootstock vigour on water relations, and vegetative and productive performance of 'Pink Lady' apple (Malus domestica Borkh.) trees in central Sicily. In a first field trial, trees on MM.106 rootstock were subjected to: Conventional irrigation (CI), maintaining soil moisture above $80 \%$ of field capacity; PRD irrigation, where only one alternated side of the rootzone received $50 \%$ of the CI irrigation water; and continuous deficit irrigation (DI), where $50 \%$ of the CI water was equally applied to both sides of the rootzone. In a second trial, trees on M.9 or MM.106 were subjected to CI and PRD irrigation. PRD reduced stomatal conductance ( $\mathrm{g}_{\mathrm{s}}$ ) more consistently in trees on MM.106 than in trees on M.9, but maintained relative water content (RWC) to the levels of CI. DI induced greater $\mathrm{g}_{\mathrm{s}}$ reductions than PRD and lower RWC than CI and PRD. Rootstock vigour did not influence plant response to irrigation strategy. PRD induced some reduction in fruit number but no change in yields and fruit quality compared with CI, whereas DI reduced fruit size and marketable yields. Significant reductions in shoot and leaf growth were induced by DI, whereas only leaf growth was affected by PRD. Our observations indicate that responses induced by PRD are due to a combination of the amount and way of applying water, and not just to reductions in irrigation volumes, suggesting a possible use of PRD for increasing apple water-use efficiency in Mediterranean environments.
\end{abstract}

Additional keywords: leaf area, peel colour, relative water content, shoot length, soil moisture, stomatal conductance.

\section{Introduction}

Fruit production in semi-arid climates is often characterised by high evapotranspiration, increased soil salinity, and limited water availability. These conditions are already widespread and may be expected to increase in scale and severity in the future mainly due to the increasing competition for water between agriculture and municipalities, especially in the Mediterranean regions. For this reason, maximising yields with minimal irrigation inputs (i.e. increasing plant water-use efficiency) becomes essential.

Plants growing under water deficit conditions can partially maintain cell turgor by closing stomata (Parker and Pallardy 1985). Yet, stomatal closure for varying periods of time impairs $\mathrm{CO}_{2}$ assimilation and may reduce the structural and energetic support for growth (Hsiao 1973). Water deficit may also alter partitioning between vegetative and reproductive sinks according to each organ's ability to attract photoassimilates. Seeds and fruits are in fact stronger sinks than shoot apices (Wardlaw 1990) and, under drought and limiting assimilation rates, vegetative growth should be reduced more and earlier than reproductive growth (Higgs and Jones 1991). In turn, contained vegetative growth may result in less shading of fruiting wood, better light distribution within the canopy, and less need for pruning. In addition, water limitation can have beneficial consequences on fruit production, such as increased return bloom (Caspari et al. 1994) and lower fresh to dry weight ratio (Shackel et al. 2000).
Also, with the introduction of high-density plantings and the consequently greater exploitation of water and nutrients, it is becoming increasingly important to optimize tree spacing, irrigation, and fertiliser distribution, and to understand root growth dynamics and how this links with the canopy. Adaptation to changes in abiotic and biotic factors may occur with an increase in the amount of root produced relative to the growth of the shoot, i.e. a change in the root:shoot ratio (Landsberg and Jones 1981). In apple (Malus domestica Borkh.), rootstock vigour seems to affect partitioning to root growth (Stutte et al. 1994), especially in response to drought (Atkinson et al. 1999). Specifically, apple trees on MM.111, a vigorous rootstock, exhibit higher root:shoot dry matter ratios than those on M.9 (Stutte et al. 1994) and this may represent an advantage for exploiting limiting water resources.

Regulated deficit irrigation (RDI) is a technique that was developed to contain excessive shoot growth and minimise irrigation inputs for fruit production, particularly in areas where water is a limiting resource. It consists in applying water inputs at a deficit during certain periods to produce a moderate drought stress and to obtain reductions in vegetative growth, along with some beneficial consequences on fruit quality. Results of RDI experiments have been promising in certain regions and for some fruit crops, such as peach (Prunus persica L.) (Chalmers et al. 1981), pear (Pyrus communis L.) 
(Mitchell et al. 1984, 1989; Caspari et al. 1994), French prune (Prunus domestica L.) (Lampinen et al. 1995), and olive (Olea europea L.) (Goldhamer 1997). In those species, vegetative and reproductive growth occur in different periods, allowing for control of shoot growth without any decrease in fruit size or yields (Chalmers 1989). On the other hand, apple fruits and shoots grow concurrently (Forshey et al. 1983) and water deficit reduces fruit size and yields, irrespective of timing (Lötter et al. 1985; Ebel et al. 1993, 1995; Mpelasoka et al. 2001).

Partial rootzone drying (PRD) is an irrigation technique that was recently developed in Australia for grapes (Vitis vinifera L.) (Dry et al. 1996; Dry and Loveys 1998). With PRD only one half of the rootzone is irrigated, whereas the other half is not. The physiological basis for PRD is that roots in drying soil produce abscisic acid (ABA), which is translocated to the shoots, indicating a developing soil-water deficit (Dry et al. 1996). In the leaves, ABA induces partial stomatal closure, which reduces transpiration and may increase water-use efficiency, whereas at the shoot meristem, ABA may reduce shoot extension. However, as the other half of the rootzone is kept well watered, the effect on plant water potential is minimal (Gowing et al. 1990) and other metabolic and physiological processes associated with water stress are not affected (Dry et al. 1996, 2000). The technique relies on cyclical wetting and drying of parts of the rootzone in order to maintain root-derived ABA signals (Zhang and Davies 1987). Yet, fruit yield, stomatal conductance $\left(\mathrm{g}_{\mathrm{s}}\right)$, and shoot growth of raspberries (Rubus idaeus L.) were similar in alternated and fixed (no switching of wet and dry sides) PRD (Grant et al. 2004).

Recent observations on 'Braeburn', 'Fuji', and 'Gala' apples indicated that PRD may allow for good fruit final size and yields, along with substantial reductions in irrigation inputs (Caspari et al. 2004a, 2004b; Einhorn and Caspari 2004; Lombardini et al. 2004). The objective of this work was to study in detail the effects of PRD on the growth of 'Pink Lady' apple trees on two rootstocks, M.9 and MM.106, differing in their vigour in the Mediterranean climate of central Sicily. Soil moisture and tree water relations were also examined to acquire useful information on the mechanisms underlying the plant's response to water regimes. For this one-season-long detailed investigation, growth performance was estimated by destructive sampling of entire trees.

\section{Materials and methods}

\section{Plant material and experimental design}

The study was conducted in 2005 near Caltavuturo $\left(37^{\circ} 49^{\prime} \mathrm{N}\right.$; $850 \mathrm{~m}$ a.s.1.), in central Sicily. Plant material consisted of 5-yearold 'Pink Lady' apple trees, trained to a central leader, planted in north-south oriented single rows, and spaced at $3.5 \mathrm{~m}$ between rows and $1 \mathrm{~m}$ within rows. Soil type was a sandy clay loam $(53.3 \%$ sand, $17.6 \%$ silt, and $29.1 \%$ clay) with $\mathrm{pH} 7.3$ and $1.8 \%$ active carbonates. At field capacity, soil water content was around $0.26 \mathrm{~m}^{3} / \mathrm{m}^{3}$ and soil water tension around $-17 \mathrm{kPa}$. Trees were drip irrigated and grown under conventional cultural practice. Fruit thinning was done by hand on 25 May (40 days after bloom), leaving 1-2 fruits per spur.
Due to the number of trees and amount of work/time required by destructive and non-destructive measurements, the study was split into two separate field trials. In the first trial, 18 trees from the same row, grown on MM.106 rootstock, uniform in size, and arranged in a randomised block design with 3 replicates, each of 2 trees per irrigation treatment, were selected and labelled. Contiguous irrigation treatments were separated by 2 buffer trees. In June, 3 irrigation treatments were imposed: (1) conventional irrigation treatment $(\mathrm{CI})$, where all drip emitters (one every meter of line, located in between consecutive trees and delivering $8 \mathrm{~L} / \mathrm{h}$ ) were left open so that trees received water on both north and south sides of the rootzone; (2) PRD treatment, where drip emitters on one side of each tree were closed so that trees received $50 \%$ of CI water only on one alternated side of the rootzone; (3) continuous deficit irrigation treatment (DI), where all drip emitters, with reduced delivery rate $(4 \mathrm{~L} / \mathrm{h})$, were left open so that trees received $50 \%$ of $\mathrm{CI}$ water on both sides of the rootzone. The interval between irrigation events and the duration of each event (max. $4 \mathrm{~h}$ ) were adjusted to maintain soil moisture above $80 \%$ of field capacity $(-50 \mathrm{kPa})$ in the rootzone of CI trees but avoid spreading of wet areas into the dry sides of PRD trees. Wet and dry sides of PRD trees were alternated every $2-3$ weeks when soil water tension in the dry side reached values of approximately -100 to $-110 \mathrm{kPa}$.

In the second trial, a set of 49 Pink Lady apple trees, 22 grown on M.9 and 27 on MM.106 rootstock, was used. Trees were located in the same plot as the first trial and arranged in a randomised block design with 3 replicates each of 3-5 trees per rootstock-irrigation combination. Contiguous irrigation treatments within each block were set on the same row and were separated by 2 buffer trees, whereas blocks were separated by at least 2 buffer rows. In this trial, only CI and PRD irrigation treatments were imposed as described above.

\section{Soil and plant water status}

Climate parameters were monitored with a $\mu$ Metos weather station (Pessl, Austria) positioned within the experimental plot. Reference evapotranspiration $\left(\mathrm{ET}_{0}\right)$ was determined according to the FAO Penman-Monteith method. Soil water tension (SWT) was monitored continuously at a fixed depth of $0.40 \mathrm{~m}$ with Watermark sensors (Irrometer Co.; Riverside, CA, USA) directly connected to the weather station. Soil moisture was assumed to be similar in the two field trials (same plot) and a total of 6 sensors were positioned in 2 replicates of the 3 treatments of Trial 1.

Stomatal conductance $\left(\mathrm{g}_{\mathrm{s}}\right)$ was monitored weekly from mid July until mid Oct. using an AP4 Delta-T porometer (Delta-T Devices; Cambridge, UK). On each date, the device was calibrated and $g_{s}$ was measured between 10:00 hours and 12:00 hours on two mature, sun-exposed leaves per tree, each from an opposite side (east or west) of the canopy. Sampling dates were differed by 1-3 days for the 2 trials.

On 24 Aug. and 7 Sept., 2 leaves similar to those used for $g_{s}$ measurements were wrapped in parafilm and aluminum foil, detached, enclosed in zip-lock bags, and transported in ice to the laboratory for determination of fresh weight (FW). Leaf samples were rehydrated for $24 \mathrm{~h}$ in the dark for determination of turgid weight (TW) and subsequently oven-dried at $60^{\circ} \mathrm{C}$ to 
constant weight for determination of dry weight (DW). Relative water content (RWC) was calculated as:

$$
\mathrm{RWC}=[(\mathrm{FW}-\mathrm{DW}) /(\mathrm{TW}-\mathrm{DW})] \times 100
$$

Fruit growth, yield, and quality

Fruit growth was estimated by measuring weekly height and width with a digital caliper on one fruit per tree. Fruit was harvested on 3 (Trial 1) and 7 November (Trial 2), and total fruit number and yield per tree were determined in the field. In the laboratory, each fruit was weighed, measured in height and width, and photographed with a digital camera. Digital images were used to determine percentage and intensity of peel red colour. Specifically, we used an algorithm that converts images from RGB to CIE $\mathrm{L}^{*} \mathrm{a}^{*} \mathrm{~b}^{*}$ format, extracts the fruit from the image (removing the image background), separates the total fruit area into 2 subregions, cover colour (closer to red) and ground colour (closer to green) according to an adjustable green-red threshold, and quantifies colour characteristics of each region as the weighed distance of each pixel in the image from pure green (ground colour) or pure red (cover colour). The output is an index for the cover colour ranging from 0 (no red) to 1 (red) and an index for the ground colour ranging from 0 (no green) to 1 (green). Percentage of cover colour was calculated dividing the number of pixels of the red region by the number of pixels of the entire fruit area. Subsequently, a subset of 15 fruits per tree was used to determine flesh firmness with a manual pressure tester mounting an 11-mm tip (TR di Turoni \& Co.; Forlì, Italy), total soluble solids (TSS) with an Atago Palette PR-32 digital refractometer (Atago Co., Ltd; Tokyo, Japan), juice $\mathrm{pH}$ and titratable acidity (expressed in $\mathrm{g}$ malic acid/L) with a Crison $\mathrm{S}$ compact titrator (Crison Instruments, SA; Alella, Barcelona, Spain), and starch pattern index with Lugol staining. Stained fruit sections were photographed and digital image analysis was used to quantify staining with an index ranging from 0 (no staining) to 1 (fully stained).

\section{Vegetative growth}

After fruit harvest, trunk circumference was measured at $\sim 15 \mathrm{~cm}$ above the graft union, trees were defoliated, all leaves of each tree were weighed, and a subsample of 15 leaves per tree was transported to the laboratory for determination of area, and fresh and dry weight. The leaf subsamples were photographed and their area was measured by digital image analysis; leaf area of subsamples was used to establish a correlation with leaf weight and estimate total leaf area per tree. Yield efficiency and crop load were expressed as kilogram or number of fruit per trunk cross-sectional area (TCSA) or leaf area. Subsequently, entire above-ground wood structures (trunk, limbs, and shoots) were cut at the ground level, and photographed with the digital camera against a white background from plan and side views for later acquisition of 2- and 3-dimensional measurements. A measuring tape of known length was included in the picture as a reference for subsequent size adjustments. After all images were acquired, wood structures were cut, weighed, and ovendried at $60^{\circ} \mathrm{C}$ to a constant weight. Digital images were edited as described in Lo Bianco et al. (2003) to determine total shoot length and diameter. Briefly, the background was manually removed from original JPEG images and clean images were saved as binary TIFF files. ROOTEDGE software (Iowa State University Foundation Inc.; Ames, IA, USA) was used to scan TIFF images and determine shoot length and diameter. The erosion function of the software was used to separate the seasonal growth from older wood according to diameter category.

The original images were also used to calculate average internode length (dividing shoot length by number of nodes) from 3 shoots per tree, canopy spread area (marked as a circle or ellipse enclosing all stems in the plan views), and canopy height. Canopy shape of the young apple trees resembled a cone. Hence, canopy volume was estimated as follows:

$$
\text { Volume }=(\text { spread area } \times \text { height }) / 3
$$

Canopy density was calculated as the total length of wood portions per unit of volume.

Only in Trial 2, root systems were excavated with the aid of a power shovel and soil was removed first by pressure washing and afterwards by immersing in water. The amount of roots recovered (mainly coarse) was weighed before and after oven-drying at $60^{\circ} \mathrm{C}$ to constant weight.

\section{Data analysis}

Yield, fruit quality, and growth data were compared by one-way analysis of variance for Trial 1, and by two-way analysis of variance (with rootstock and irrigation treatment as main factors) using SYSTAT procedures (Systat Software Inc.; Richmond, CA, USA). Fruit quality data were also analysed using crop load as covariate to correct for differences in fruit number among treatments. However, since differences in fruit number were mainly due to late fruit drop determined by the irrigation treatments, unadjusted means and statistics with no covariate in the model are reported in tables. Repeated-measures analysis of variance followed by orthogonal polynomial contrasts was used to evaluate differences in $\mathrm{g}_{\mathrm{s}}$ and fruit growth between treatments and sampling dates.

\section{Results}

The irrigation season started on 15 July ( 5 days after the last relevant precipitation event and 92 days after bloom) and ended on 29 Aug. (Fig. 1). The total irrigation volume was $220 \mathrm{~mm}$ for CI and $110 \mathrm{~mm}$ for DI and PRD distributed over 24 events (a total of $768 \mathrm{~L}$ of irrigation water per CI tree) for both trials. Atmospheric water demand indicated by $\mathrm{ET}_{0}$ was fully covered by precipitations until 10 May (Fig. 1). During the remaining growth season (throughout fruit development and until harvest) cumulated water inputs to CI trees (precipitations + irrigations) covered $50-65 \%$ of $\mathrm{ET}_{0}$ (Fig. 1).

In CI trees, SWT showed fluctuations due to wetting and drying cycles between consecutive irrigation events, but staying generally above $-50 \mathrm{kPa}$ ( $~ 80 \%$ of field capacity) during the irrigation period, with negative peak values of $-66 \mathrm{kPa}$ only before the irrigation season started (Fig. 2a). In DI trees, SWT followed the same changes as in CI trees, reaching progressively lower values of $-80 \mathrm{kPa}$ towards the middle and end of the irrigation season (Fig. 2a). In PRD trees, wet and dry sides were alternated on 31 July and 25 Aug. During the irrigation 
period, SWT of the wet side remained generally above $-50 \mathrm{kPa}$, while SWT of the dry side reached values of -110 to $-115 \mathrm{kPa}$ at the end of each dry cycle (Fig. 2b).



Fig. 1. Cumulative daily water inputs (precipitation and irrigation to control trees) and atmospheric demand (reference evapotranspiration, $\mathrm{ET}_{0}$ ) during the growing season (2005) near Caltavuturo ( $37^{\circ} 49^{\prime} \mathrm{N} ; 850 \mathrm{~m}$ a.s.1.), Sicily.

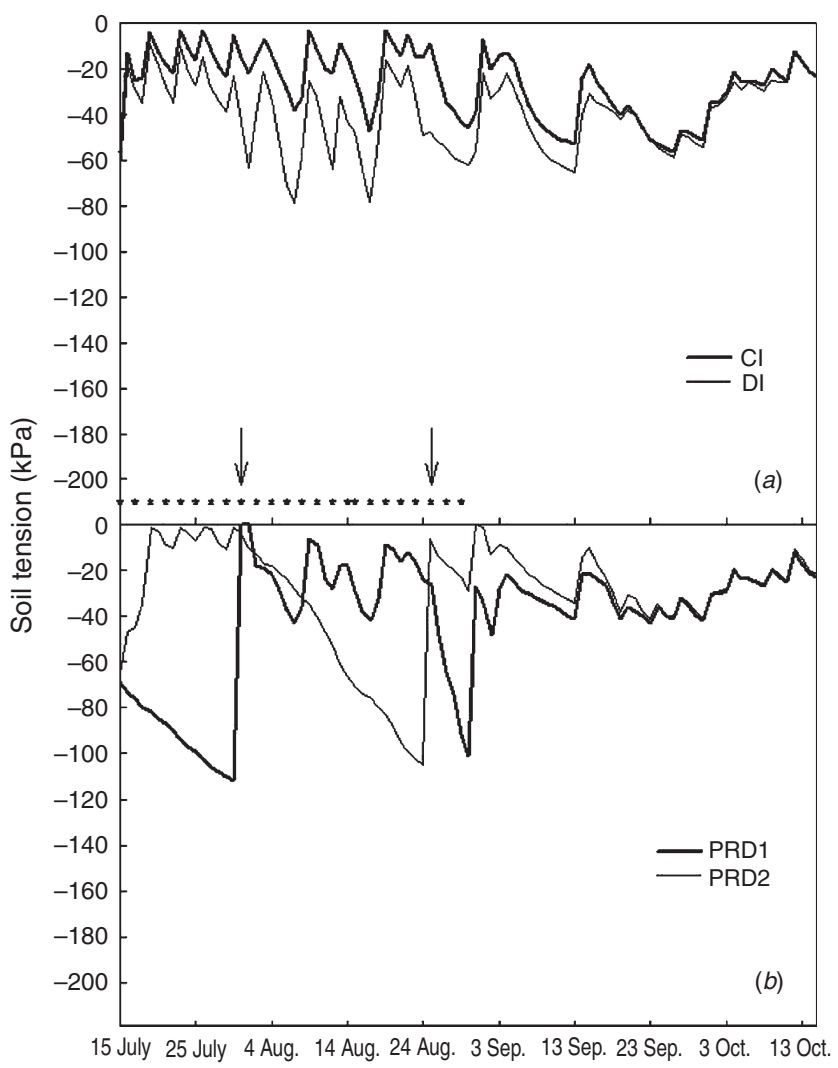

Fig. 2. Soil water tension at $0.40 \mathrm{~m}$ depth for conventional irrigation (CI), deficit irrigation (DI), and partial rootzone drying (PRD) treatments. Asterisks indicate irrigation events and arrows indicate a switch of the irrigated side for PRD. Soil moisture was assumed to be similar in both Trial 1 and 2 (contiguous plots).
Trial 1

On 24 Aug., RWC of DI trees was significantly lower than RWC of CI and PRD trees (Table 1). DI irrigation reduced $g_{s}$ from 18 July until 5 Sept., with the exception of 22 Aug., and with maximum reductions of $65 \%$ over CI irrigation, whereas PRD irrigation yielded intermediate $\mathrm{g}_{\mathrm{s}}$ with significant reductions of $31 \%$ over CI irrigation on 1 Aug. (Fig. 3a). As the season progressed, only fruits of DI trees tended to be smaller than those of CI trees, although differences were non-significant (Fig. 3b). Fruit RGR of DI trees was significantly reduced compared with that of CI trees on 14 Aug. (Fig. 3c).

Yields of trees from the three irrigation treatments were similar, whereas number of fruits in CI and DI was greater than in PRD (Table 2). Yield efficiency and crop load calculated on a TCSA basis were lower in PRD trees than in the other two treatments, whereas differences among treatments were non-significant when yield efficiency and crop load were expressed on a leaf area basis (Table 2). Differences in crop load were mainly due to late-summer fruit drop and not to differences in initial number of spurs or fruit set.

Among all fruit quality attributes, only weight and acidity were significantly reduced in DI trees compared with the other two irrigation treatments (Table 3), although those differences were cancelled when crop load was used as a covariate in the ANOVA model. Also, over $90 \%$ of DI fruits fell into the $<70 \mathrm{~mm}$ diameter class, whereas only $27 \%$ of PRD and $33 \%$ of CI fruits fell into the same diameter class.

Vegetative growth was generally reduced by DI irrigation, and only in part by PRD. Specifically, tree size and current shoot length and weight were significantly reduced by DI irrigation, whereas leaf growth was significantly reduced by both PRD and DI treatments compared with CI irrigation (Table 4).

Trial 2

RWC of both rootstocks and both irrigation treatments was similar on 24 Aug., during the irrigation period, and on 7 Sept., after rainfall resumption (Table 1). As for $g_{s}$, repeatedmeasures ANOVA revealed a significant rootstock effect $(P<0.001)$, a significant irrigation effect $(P<0.001)$, significant variations over time $(P<0.001)$, and a significant interaction between rootstock and irrigation $(P=0.015)$. In

Table 1. Leaf relative water content (\%) of 5-year-old 'Pink Lady' apple trees grown on M.9 and MM.106 rootstocks and under conventional irrigation (CI), deficit irrigation (DI), and partial rootzone drying (PRD)

Means \pm standard errors. Means followed by the same letter are not significantly different among treatments by Tukey's multiple range test

\begin{tabular}{lrrr}
\hline Rootstock & Irrigation & 24 Aug. & 7 Sept. \\
\hline \multirow{3}{*}{ MM.106 } & Trial 1 & $86.9 \pm 1.41 \mathrm{a}$ & $80.2 \pm 1.12$ \\
& PRD & $86.2 \pm 1.47 \mathrm{a}$ & $80.7 \pm 1.13$ \\
& DI & $83.4 \pm 1.07 \mathrm{~b}$ & $80.1 \pm 1.09$
\end{tabular}

$\begin{array}{lcll}\text { M.9 } & \text { CI } & 87.1 \pm 1.35 & 80.6 \pm 0.71 \\ \text { MM.106 } & \text { PRD } & 85.7 \pm 1.33 & 81.0 \pm 1.30 \\ & \text { CI } & 86.6 \pm 1.06 & 80.1 \pm 1.16 \\ & \text { PRD } & 86.7 \pm 0.83 & 80.4 \pm 0.83\end{array}$




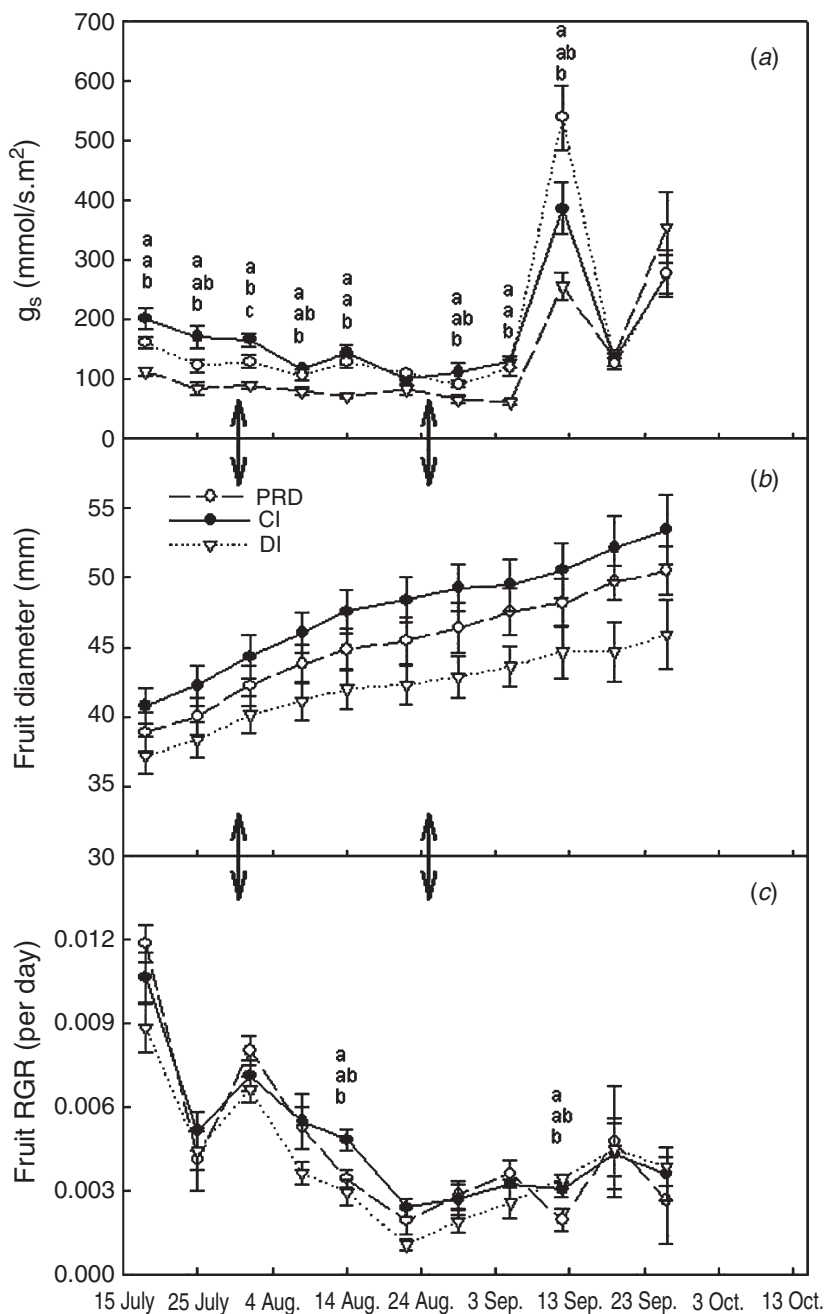

Fig. 3. (a) Stomatal conductance $\left(\mathrm{g}_{\mathrm{s}}\right),(b)$ average fruit diameter, and $(c)$ fruit relative growth rate (RGR) of 5-year-old 'Pink Lady' apple trees under partial rootzone drying (PRD), conventional irrigation (CI), and deficit irrigation (DI). Error bars indicate standard errors of the means. When present, means followed by the same letter at each date are not significantly different among irrigation treatments by Tukey's multiple range test. Data from Trial 1.

Table 2. Production and water-use efficiency (WUE) of 5-year-old 'Pink Lady' apple trees on MM.106 rootstock under conventional irrigation (CI), deficit irrigation (DI), and partial rootzone drying (PRD) Means \pm standard errors. Within each row, means followed by the same letter are not significantly different among irrigation treatments by Tukey's multiple range test. Data from Trial 1

\begin{tabular}{lllc}
\hline & \multicolumn{1}{c}{ PRD } & \multicolumn{1}{c}{ CI } & DI \\
\hline Yield (kg/tree) & $11.5 \pm 0.60$ & $15.3 \pm 1.90$ & $12.1 \pm 1.20$ \\
No. of fruits per tree & $58.0 \pm 2.47 \mathrm{~b}$ & $78.2 \pm 9.20 \mathrm{ab}$ & $83.2 \pm 5.03 \mathrm{a}$ \\
Yield efficiency ( $\mathrm{kg} / \mathrm{cm}^{2}$ TCSA) & $0.38 \pm 0.02 \mathrm{~b}$ & $0.61 \pm 0.01 \mathrm{a}$ & $0.59 \pm 0.03 \mathrm{a}$ \\
Crop load (no. fruit $/ \mathrm{cm}^{2}$ TCSA) & $1.96 \pm 0.19 \mathrm{~b}$ & $3.46 \pm 0.68 \mathrm{ab}$ & $4.12 \pm 0.28 \mathrm{a}$ \\
Yield/leaf area $\left(\mathrm{kg} / \mathrm{m}^{2}\right)$ & $2.76 \pm 0.12$ & $3.21 \pm 0.39$ & $3.85 \pm 0.35$ \\
Fruit no./leaf area (no. fruit $\left./ \mathrm{m}^{2}\right)$ & $15.0 \pm 1.93$ & $20.1 \pm 5.54$ & $27.4 \pm 2.67$ \\
Irrigation inputs (ML/ha) & 1.10 & 2.19 & 1.10 \\
WUE (t/ML) & 29.9 & 19.9 & 31.5 \\
\hline
\end{tabular}

Table 3. Fruit quality attributes of 5-year-old 'Pink Lady' apple trees under conventional irrigation (CI), deficit irrigation (DI), and partial rootzone drying (PRD)

Means \pm standard errors. Within each row, means followed by the same letter are not significantly different among irrigation treatments by Tukey's multiple range test. Data from Trial 1

\begin{tabular}{llll}
\hline & \multicolumn{1}{c}{ PRD } & \multicolumn{1}{c}{ CI } & \multicolumn{1}{c}{ DI } \\
\hline Weight $(\mathrm{g})$ & $198 \pm 6.71 \mathrm{a}$ & $196 \pm 6.12 \mathrm{a}$ & $146 \pm 4.50 \mathrm{~b}$ \\
TSS $\left({ }^{\circ}\right.$ Brix $)$ & $14.9 \pm 0.68$ & $15.4 \pm 0.40$ & $14.7 \pm 0.45$ \\
$\mathrm{pH}$ & $3.01 \pm 0.09$ & $3.02 \pm 0.03$ & $2.93 \pm 0.04$ \\
Acidity $(\mathrm{g} / \mathrm{L})$ & $1.52 \pm 0.18 \mathrm{ab}$ & $1.67 \pm 0.08 \mathrm{a}$ & $1.23 \pm 0.06 \mathrm{~b}$ \\
Water content $(\%)$ & $76.8 \pm 0.70$ & $76.0 \pm 0.56$ & $76.0 \pm 0.47$ \\
Flesh firmness $\left(\mathrm{kg} / \mathrm{cm}^{2}\right)$ & $6.77 \pm 0.11$ & $6.73 \pm 0.15$ & $6.77 \pm 0.07$ \\
Starch pattern index & $0.17 \pm 0.01$ & $0.17 \pm 0.01$ & $0.18 \pm 0.01$ \\
Peel colour index & $0.87 \pm 0.004$ & $0.87 \pm 0.004$ & $0.87 \pm 0.003$ \\
Peel red colour $(\%)$ & $92.9 \pm 2.15$ & $91.2 \pm 1.97$ & $88.0 \pm 2.10$ \\
\hline
\end{tabular}

Table 4. Vegetative growth of 5-year-old 'Pink Lady' apple trees under conventional irrigation (CI), deficit irrigation (DI), and partial rootzone drying (PRD)

Means \pm standard errors. Within each row, means followed by the same letter are not significantly different among irrigation treatments by Tukey's multiple range test. Data from Trial 1

\begin{tabular}{llll}
\hline & \multicolumn{1}{c}{ PRD } & \multicolumn{1}{c}{ CI } & \multicolumn{1}{c}{ DI } \\
\hline Tree height $(\mathrm{m})$ & $2.23 \pm 0.04 \mathrm{a}$ & $2.21 \pm 0.13 \mathrm{a}$ & $1.91 \pm 0.06 \mathrm{~b}$ \\
Canopy spread area $\left(\mathrm{m}^{2}\right)$ & $3.97 \pm 0.16 \mathrm{a}$ & $4.12 \pm 0.24 \mathrm{a}$ & $3.04 \pm 0.15 \mathrm{~b}$ \\
Canopy volume $\left(\mathrm{m}^{3}\right)$ & $3.07 \pm 0.14 \mathrm{a}$ & $3.08 \pm 0.30 \mathrm{a}$ & $1.93 \pm 0.13 \mathrm{~b}$ \\
Canopy density $\left(\mathrm{m}^{3} \mathrm{~m}^{3}\right)$ & $17.4 \pm 1.45$ & $15.5 \pm 0.84$ & $16.4 \pm 0.52$ \\
Shoot length $(\mathrm{m} / \mathrm{tree})$ & $34.0 \pm 4.98 \mathrm{a}$ & $36.9 \pm 5.26 \mathrm{a}$ & $21.5 \pm 1.71 \mathrm{~b}$ \\
Shoot diameter $(\mathrm{cm})$ & $0.87 \pm 0.02$ & $0.90 \pm 0.02$ & $0.90 \pm 0.02$ \\
Shoot weight $(\mathrm{kg} / \mathrm{tree})$ & $3.95 \pm 0.44 \mathrm{a}$ & $4.37 \pm 0.51 \mathrm{a}$ & $2.27 \pm 0.11 \mathrm{~b}$ \\
Internode length $(\mathrm{cm})$ & $3.96 \pm 0.14$ & $4.19 \pm 0.28$ & $3.68 \pm 0.22$ \\
Leaf area $\left(\mathrm{m}^{2} / \mathrm{tree}\right)$ & $3.68 \pm 0.39 \mathrm{~b}$ & $5.51 \pm 0.50 \mathrm{a}$ & $3.14 \pm 0.33 \mathrm{~b}$ \\
Leaf weight $(\mathrm{kg} / \mathrm{tree})$ & $0.86 \pm 0.09 \mathrm{~b}$ & $1.34 \pm 0.12 \mathrm{a}$ & $0.77 \pm 0.07 \mathrm{~b}$ \\
Leaf density $\left(\mathrm{m}^{2} / \mathrm{m}\right)$ & $0.12 \pm 0.01 \mathrm{~b}$ & $0.16 \pm 0.01 \mathrm{a}$ & $0.15 \pm 0.01 \mathrm{ab}$ \\
Leaf water content $(\%)$ & $52.4 \pm 0.53$ & $51.4 \pm 0.40$ & $52.2 \pm 0.48$ \\
\hline
\end{tabular}

M.9, $\mathrm{g}_{\mathrm{s}}$ was greater in CI than in PRD at the beginning and during the middle of the irrigation period (from 10 Aug. to 7 Sept.) but recovered to similar levels after rainfall resumption by mid Sep (Fig. 4a). The trend was inverted, with greater $\mathrm{g}_{\mathrm{s}}$ in PRD trees, at the end of the observation period on 12 Oct. (Fig. 4a). In MM.106, $\mathrm{g}_{\mathrm{s}}$ was greater in CI than PRD during the entire irrigation period and even on two dates (29 Sept. and 12 Oct.) after rainfall resumption (Fig. 4b).

As for fruit size, repeated-measures ANOVA revealed a nonsignificant rootstock effect $(P=0.534)$, a significant irrigation effect $(P=0.047)$, significant variations over time $(P<0.001)$, but no significant interaction between rootstock and irrigation. In this case, the first degree polynomial contrast explained $\sim 99 \%$ of the variability over time, indicating a linear increase in fruit size. In particular, CI fruit was larger than PRD fruit on three dates, 3 and 24 Aug., and 21 Sept. (Fig. 5a). Fruit RGR did not seem to explain the observed differences in fruit size, on the contrary, being higher in PRD fruit only on 29 Sept. (Fig. 5b). In this case, the first degree polynomial contrast explained $65 \%$ of the variability indicating a linear decrease of RGR with time. 


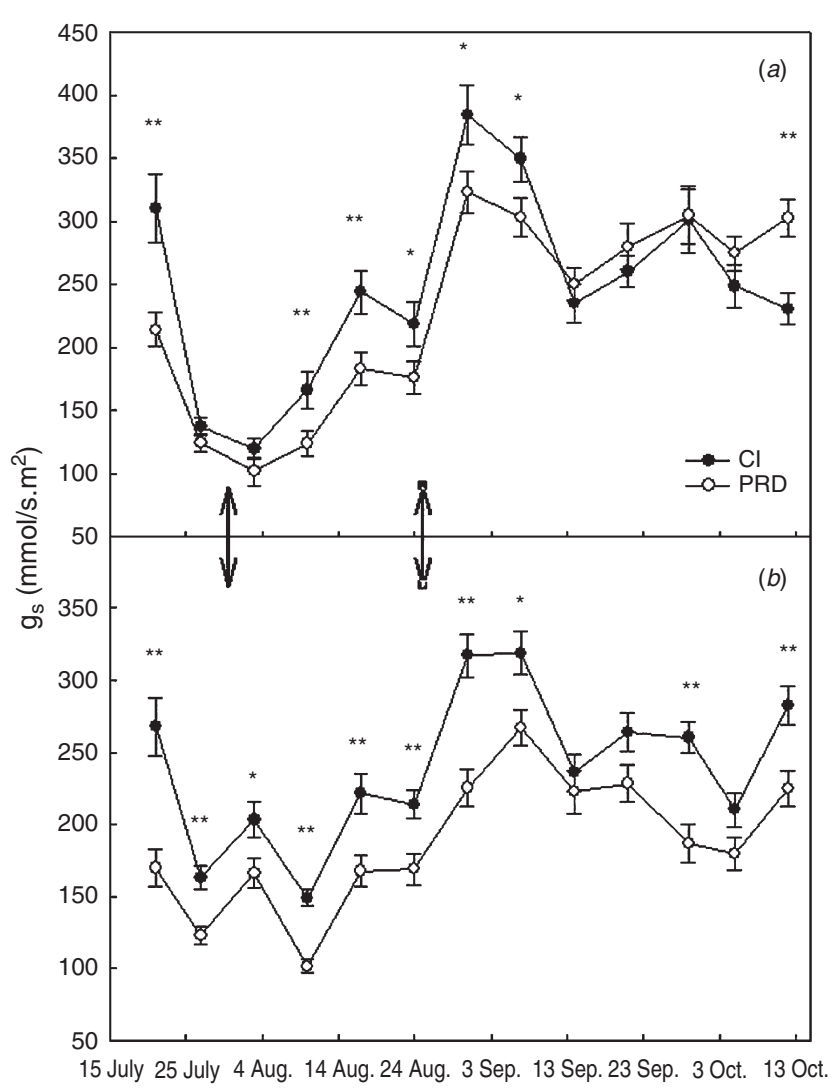

Fig. 4. Stomatal conductance $\left(\mathrm{g}_{\mathrm{s}}\right)$ of 5-year-old 'Pink Lady' apple trees grown on (a) M.9 and (b) MM.106 rootstocks and under conventional irrigation (CI) and partial rootzone drying (PRD). Error bars indicate standard errors of the means. $* P<0.05$ and $* * P<0.01$ indicate significant differences between irrigation treatments for each date. Data from Trial 2.

Yields, number of fruit, yield efficiency, and crop load were similar in both rootstocks and both irrigation treatments, although the M.9 rootstock and the PRD irrigation tended to reduce production parameters (Table 5). Also, external fruit quality attributes, such as weight, size, peel colour, and percentage of peel red colour, were similar in both rootstocks and both irrigation treatments, with the sole exception of a reduced fruit weight for trees on MM.106 (Table 6). As for internal quality attributes, fruit of trees on M.9 was firmer and less acidic than that of trees on MM.106, and PRD fruit was firmer than CI fruit (Table 6). Water content and TSS were similar in fruit of the two irrigation

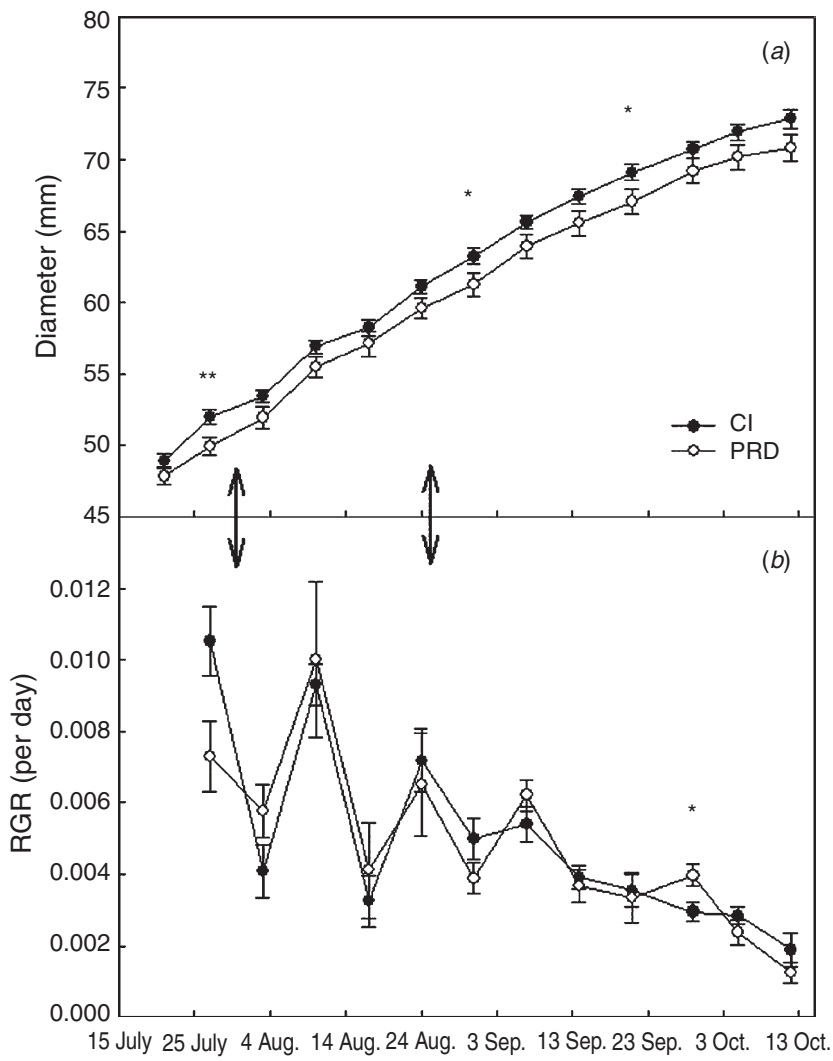

Fig. 5. (a) Average fruit diameter and (b) fruit relative growth rate (RGR) of 5-year-old 'Pink Lady' apple trees grown on M.9 and MM.106 rootstocks and under conventional irrigation (CI) and partial rootzone drying (PRD). Rootstock and rootstock $\times$ irrigation effects were non-significant and data of the two rootstocks were pooled together. Error bars indicate standard errors of the means. ${ }^{*} P<0.05$ and $* * P<0.01$ indicate significant differences between irrigation treatments for each date. Data from Trial 2.

treatments. In trees on M.9, 29\% of CI fruits and 39\% of PRD fruits fell into the <70-mm-diameter class; whereas in trees on MM.106, $28 \%$ of CI fruits and $50 \%$ of PRD fruits fell into the $<70$-mm-diameter class.

Rootstock vigour affected several parameters concerning tree vegetative growth. Specifically, canopy height, spread area, and volume were greater in trees on MM.106 than in trees on M.9 (Table 7). Also, root dry weight tended to be greater $(P=0.054)$ in MM.106 (2.89 kg) than in M.9 $(2.31 \mathrm{~kg})$. On the other hand, the

Table 5. Production and water-use efficiency (WUE) of 5-year-old 'Pink Lady' apple trees grown on M.9 and MM.106 rootstocks and under conventional irrigation (CI) and partial rootzone drying (PRD)

Means \pm standard errors. Yield efficiency and crop load are expressed on a leaf area basis. Data from Trial $2 . * P<0.05 ; * * P<0.01 ;$ n.s., not significant

\begin{tabular}{|c|c|c|c|c|c|}
\hline & Yield (kg/tree) & Number of fruits & Yield efficiency $\left(\mathrm{kg} / \mathrm{m}^{2}\right)$ & Crop load (n. fruits $/ \mathrm{m}^{2}$ ) & WUE $(\mathrm{t} \cdot \mathrm{ML})$ \\
\hline M.9 & $8.0 \pm 1.61$ & $40.2 \pm 9.1$ & $1.47 \pm 0.27$ & $7.72 \pm 1.58$ & 13.9 \\
\hline МM.106 & $12.9 \pm 2.01$ & $72.0 \pm 10.1$ & $1.76 \pm 0.23$ & $9.59 \pm 1.15$ & 22.4 \\
\hline Rootstock effect ${ }^{\mathrm{A}}$ & n.s. & $*$ & n.s. & n.s. & - \\
\hline PRD & $9.0 \pm 1.85$ & $48.0 \pm 10.1$ & $1.44 \pm 0.25$ & $7.87 \pm 1.44$ & 23.4 \\
\hline Irrigation effect ${ }^{\mathrm{A}}$ & n.s. & n.s. & n.s. & n.s. & - \\
\hline
\end{tabular}

\footnotetext{
${ }^{\mathrm{A}}$ Main effect from two-way analysis of variance (rootstock $\times$ irrigation interaction non-significant).
} 
Table 6. Fruit quality attributes of 5-year-old 'Pink Lady' apple trees grown on M.9 and MM.106 rootstocks and under conventional irrigation (CI) and partial rootzone drying (PRD)

Means \pm standard errors. Data from Trial $2 .{ }^{*} P<0.05 ; * * P<0.01$; n.s., not significant

\begin{tabular}{|c|c|c|c|c|c|}
\hline & Fresh weight (g) & Diameter (mm) & Peel colour index & Peel colour $(\%)$ & Water cont. $(\%)$ \\
\hline M.9 & $199 \pm 8.42$ & $72.3 \pm 2.24$ & $0.94 \pm 0.01$ & $90.7 \pm 1.30$ & $82.0 \pm 0.22$ \\
\hline MM.106 & $179 \pm 4.77$ & $70.9 \pm 0.82$ & $0.93 \pm 0.01$ & $92.3 \pm 1.26$ & $82.0 \pm 0.12$ \\
\hline Rootstock effect ${ }^{\mathrm{A}}$ & $*$ & n.s. & n.s. & n.s. & n.s. \\
\hline CI & $189 \pm 4.49$ & $71.6 \pm 1.52$ & $0.93 \pm 0.01$ & $90.7 \pm 1.07$ & $82.2 \pm 0.16$ \\
\hline PRD & $187 \pm 10.2$ & $71.4 \pm 1.57$ & $0.94 \pm 0.01$ & $92.8 \pm 1.59$ & $81.7 \pm 0.13$ \\
\hline \multirow[t]{2}{*}{ Irrigation effect ${ }^{\mathrm{A}}$} & n.s. & n.s. & n.s. & n.s. & n.s. \\
\hline & Flesh firmness $\left(\mathrm{kg} / \mathrm{cm}^{2}\right)$ & Starch patt. index & $\operatorname{TSS}\left({ }^{\circ}\right.$ Brix $)$ & Acidity $(\mathrm{g} / \mathrm{L})$ & $\mathrm{pH}$ \\
\hline M.9 & $9.45 \pm 0.11$ & $0.21 \pm 0.01$ & $14.6 \pm 0.24$ & $1.94 \pm 0.07$ & $3.16 \pm 0.02$ \\
\hline MM.106 & $8.91 \pm 0.10$ & $0.19 \pm 0.01$ & $14.8 \pm 0.11$ & $2.25 \pm 0.05$ & $3.12 \pm 0.05$ \\
\hline Rootstock effect ${ }^{\mathrm{A}}$ & $* *$ & n.s. & n.s. & $* *$ & n.s. \\
\hline CI & $9.04 \pm 0.08$ & $0.20 \pm 0.01$ & $14.6 \pm 0.17$ & $2.11 \pm 0.07$ & $3.16 \pm 0.04$ \\
\hline PRD & $9.31 \pm 0.17$ & $0.20 \pm 0.01$ & $14.7 \pm 0.18$ & $2.11 \pm 0.08$ & $3.10 \pm 0.02$ \\
\hline Irrigation effect ${ }^{\mathrm{A}}$ & * & n.s. & n.s. & n.s. & n.s. \\
\hline
\end{tabular}

${ }^{\mathrm{A}}$ Main effect from two-way analysis of variance (rootstock $\times$ irrigation interaction non-significant).

Table 7. Vegetative growth of 5-year-old 'Pink Lady' apple trees grown on M.9 and MM.106 rootstocks and under conventional irrigation (CI) and partial rootzone drying (PRD)

Means \pm standard errors. Data from Trial 2. $* P<0.05 ; * * P<0.01$; n.s., not significant

\begin{tabular}{|c|c|c|c|c|}
\hline Canopy: & Height (m) & Spread area $\left(\mathrm{m}^{2}\right)$ & Volume $\left(\mathrm{m}^{3}\right)$ & Density $\left(\mathrm{m} / \mathrm{m}^{3}\right)$ \\
\hline M.9 & $1.97 \pm 0.06$ & $2.24 \pm 0.15$ & $1.50 \pm 0.12$ & $24.4 \pm 1.12$ \\
\hline МM.106 & $2.19 \pm 0.05$ & $2.93 \pm 0.18$ & $2.18 \pm 0.15$ & $26.1 \pm 1.40$ \\
\hline Rootstock effect ${ }^{\mathrm{A}}$ & $* *$ & $* *$ & $* *$ & n.s. \\
\hline CI & $2.15 \pm 0.05$ & $2.78 \pm 0.17$ & $2.02 \pm 0.14$ & $24.5 \pm 0.90$ \\
\hline PRD & $2.02 \pm 0.06$ & $2.43 \pm 0.19$ & $1.70 \pm 0.17$ & $26.3 \pm 1.63$ \\
\hline Irrigation effect ${ }^{\mathrm{A}}$ & n.s. & n.s. & n.s. & n.s. \\
\hline Shoots: & Length (m/tree) & Diameter $(\mathrm{cm})$ & Weight (kg/tree) & Internode length $(\mathrm{cm})$ \\
\hline M.9 & $22.1 \pm 1.33$ & $0.93 \pm 0.03$ & $3.08 \pm 0.08$ & $1.94 \pm 0.05$ \\
\hline MM.106 & $34.3 \pm 0.92$ & $0.92 \pm 0.03$ & $3.89 \pm 0.11$ & $2.20 \pm 0.06$ \\
\hline Rootstock effect ${ }^{\mathrm{A}}$ & $* *$ & n.s. & $* *$ & $* *$ \\
\hline CI & $30.5 \pm 2.02$ & $0.96 \pm 0.03$ & $3.68 \pm 0.14$ & $2.13 \pm 0.06$ \\
\hline PRD & $26.9 \pm 1.98$ & $0.89 \pm 0.03$ & $3.34 \pm 0.12$ & $2.03 \pm 0.07$ \\
\hline Irrigation effect ${ }^{\mathrm{A}}$ & n.s. & n.s. & $*$ & n.s. \\
\hline Leaves: & Area $\left(\mathrm{m}^{2} /\right.$ tree $)$ & Weight (kg/tree) & Water cont. (\%) & Density $\left(\mathrm{m}^{2} / \mathrm{m}\right)$ \\
\hline M.9 & $4.86 \pm 0.33$ & $1.22 \pm 0.09$ & $55.8 \pm 0.44$ & $0.22 \pm 0.01$ \\
\hline МM.106 & $7.09 \pm 0.44$ & $1.76 \pm 0.11$ & $57.7 \pm 0.46$ & $0.21 \pm 0.01$ \\
\hline Rootstock effect ${ }^{\mathrm{A}}$ & $* *$ & $* *$ & $* *$ & n.s. \\
\hline CI & $6.67 \pm 0.45$ & $1.64 \pm 0.11$ & $56.9 \pm 0.41$ & $0.22 \pm 0.01$ \\
\hline PRD & $5.41 \pm 0.43$ & $1.38 \pm 0.12$ & $56.7 \pm 0.58$ & $0.20 \pm 0.01$ \\
\hline Irrigation effect ${ }^{\mathrm{A}}$ & n.s. & n.s. & n.s. & n.s. \\
\hline
\end{tabular}

${ }^{\mathrm{A}}$ Main effect from two-way analysis of variance (rootstock $\times$ irrigation interaction non-significant).

irrigation treatment did not affect canopy size (Table 7) or root dry weight (3.01 and $2.47 \mathrm{~kg}$ for CI and $\mathrm{PRD}$, respectively; $P=0.068)$. As for current growth, shoots of trees on MM.106 showed greater cumulative length and weight, and average internode length than shoots of trees on M.9 (Table 7). PRD irrigation caused a reduction in shoot weight, whereas average shoot diameter and internode length were similar in both irrigation treatments (Table 7). In addition, trees on MM.106 showed greater leaf area, weight, and water content than trees on M.9 (Table 7). Irrigation generally did not affect leaf growth, although leaf area and weight tended to be reduced by PRD irrigation (Table 7).

\section{Discussion}

As expected, the MM.106 rootstock generally induced higher vigour, along with a tendency to bear a greater number of fruits, but only minor differences in fruit quality of the Pink Lady apple trees. On the other hand, PRD irrigation maintained yields and fruit quality to the levels of conventionally irrigated trees, 
although some reduction in yield efficiency and crop load (mainly due to late fruit drop) was observed. Vegetative growth was definitely reduced by DI irrigation, while PRD irrigation somewhat reduced shoot growth only in one of the two trials.

In Trial 2, $g_{s}$ reductions in response to the PRD treatment were rather prompt for both rootstocks. This effect should be due to relatively rapid soil drying and consequent hormonal signal. For that matter the two rootstocks seemed to behave differently as only trees on MM.106 maintained reduced $g_{s}$ levels after rainfall resumption. Although we did not measure ABA content, we can hypothesise that faster growing trees on the more vigorous rootstock may have experienced more severe deficit (greater ABA accumulation) during the irrigation period, causing a delay for $\mathrm{g}_{\mathrm{s}}$ resumption. Similar reductions of $\mathrm{g}_{\mathrm{s}}$ were reported in potted apples (Gowing et al. 1990), in olive (Wahbi et al. 2005), and in grapes (Dry and Loveys 1999; De Souza et al. 2003). Other studies conducted on field-grown apple trees reported inconsistent $g_{s}$ reductions in response to PRD (Einhorn and Caspari 2004; Lombardini et al. 2004; van Hooijdonk et al. 2004). In particular, excessive irrigation volumes (twice the predicted crop evapotranspiration) seem to cancel out the PRD response of Pink Lady apple trees (O'Connell and Goodwin 2007). Discrepancies between our results and those obtained by other authors may be partly due to a combination of evaporative demand, soil type, irrigation system, and volumes applied at each irrigation event differing in the various trials. Soil type, irrigation system, and water applied in each event contribute all together to create those conditions of separation between dry and wet sides of the rootzone, which are critical for concurrent production of hormonal signals and maintenance of adequate plant water status. In Trial $1, \mathrm{~g}_{\mathrm{s}}$ reductions of PRD trees were less remarkable and differences between PRD and CI trees were often non-significant. This may be attributed in part to the somewhat greater number of fruits per unit leaf area (and consequent assimilate demand) of trees in Trail 1 than in Trial 2.

Despite the observed reductions in $\mathrm{g}_{\mathrm{s}}$ of PRD trees, only sporadically was fruit growth affected, and final fruit size and yield per tree were similar to those of conventionally irrigated trees. On the other hand, differences in fruit number, and consequently in crop load, were mostly due to some fruit drop in Aug. noticeable only for PRD trees, but not quantified. Fruit drop was considered to be a mechanism of trees adjusting to conditions induced by PRD irrigation, and fruit quality or vegetative growth data were not corrected for differences in crop load.

Although yield efficiency and crop load of CI and DI trees tended to be higher than those of PRD trees, the percentage of marketable fruit in PRD trees remained generally similar to that of CI trees and higher than that of DI trees. Hence, if only marketable fruit is considered for calculation of yield efficiency and crop load, PRD trees can be considered certainly more efficient than DI trees. Also, if we consider the amount of marketable fruit biomass produced per litre of water supplied with irrigation, in Trial 1, PRD trees $(23.5 \mathrm{~g} / \mathrm{L})$ were more water-use efficient than CI trees $(14.2 \mathrm{~g} / \mathrm{L})$, and several times more efficient than DI trees $(4.1 \mathrm{~g} / \mathrm{L})$, whereas in Trial 2 , PRD and CI trees were almost equally efficient (17.7 and $16.4 \mathrm{~g} / \mathrm{L}$, respectively).
Fruit quality of PRD trees was also similar to that of CI trees, whereas DI irrigation decreased fruit size. These differences in fruit size can be in part explained by differences in crop load determined by the irrigation treatments. PRD trees experienced severe soil drying in one portion of the rootzone. These conditions occurred early enough during fruit development to cause some fruit drop, adjustment to a lower crop load and, as a result, fruit size similar to CI trees. In PRD trees, this crop load adjustment may have also contributed to maintaining RWC levels similar to those of CI trees. Crop load is in fact shown to affect plant response to water deficit in Japanese plum (Naor 2004). In DI trees, on the other hand, soil dried more gradually and no significant fruit drop or crop load reduction was observed; this condition generated a hydraulic signal (reduced RWC) and caused a reduction in final fruit size. Also, although we did not measure SWT at different depths, supplying irrigation water at reduced amounts $(50 \%$ of $\mathrm{CI})$ on both sides of the rootzone (DI) may have determined greater water loss by evaporation and dryer conditions in the shallow soil layers compared with other treatments.

In Trial 2, where fruits were harvested a few days earlier, fruits of PRD trees were firmer than those of CI trees, in agreement with differences detected by Leib et al. (2006) in Fuji apples. Higher flesh firmness may be considered a positive feature for handling and storage, especially since it is not attributable to differences in fruit maturation. The starch pattern index was in fact similar in the two irrigation treatments of the same trial, indicating that the irrigation regime did not affect fruit maturation timing. Other authors have observed contrasting responses for apple fruit yield and quality, depending on the season, orchard location, and climatic conditions. For example, Lombardini et al. (2004) observed a reduction in fruit size for apple trees under PRD. Also, Pink Lady apple yields and fruit size were reduced by $\mathrm{PRD}$, at least when irrigation inputs equaled predicted crop evapotranspiration (O'Connell and Goodwin 2007). However, some other studies show that PRD does not affect apple fruit yield and quality (Caspari et al. 2004a, 2004b; Einhorn and Caspari 2004; van Hooijdonk et al. 2004).

On the other hand, the effects of irrigation on vegetative growth were variable. Current growth and tree size were generally reduced by DI irrigation, whereas PRD irrigation reduced leaf growth, and current growth only in Trial 2. In both cases, the reduction in shoot growth is not associated with reductions in internode length but most likely with a lower number of internodes, which may explain some reduction in leaf area or biomass. In DI trees, vegetative growth reductions may also be explained by the higher number of fruits and crop load determining stronger competition among sinks for assimilates and water. Vegetative growth reductions, mainly in terms of reduced shoot length, were also reported in raspberry (Grant et al. 2004), grapes (Dry and Loveys 1999; Dry et al. 2000; Santos et al. 2003), olive (Wahbi et al. 2005), and potted apple (Gowing et al. 1990), while trials conducted on field-grown apple trees indicated variable responses depending on irrigation volumes (O'Connell and Goodwin 2007), or no shoot growth reduction in response to PRD (Einhorn and Caspari 2004; Lombardini et al. 2004). Discrepancies between the two trials of this study and with previous field trials could be attributable to some 
differences in crop load and associated degree of $g_{s}$ reduction in response to PRD irrigation. This is particularly evident in Trial 1, where vegetative growth reductions seem to be directly related to $\mathrm{g}_{\mathrm{s}}$ reductions.

Moreover, trees under PRD irrigation, receiving reduced amounts of water, did not invest any greater amount of carbon into root growth than CI trees; they actually tended to show reduced root dry weights, regardless of rootstock. This may be due in part to the fact that tree water status was similar for the two irrigation treatments, and in part to a possible growth-suppressing hormonal effect (i.e. residual, non-translocated ABA) in the roots of PRD trees.

Overall, this study indicates that differences among irrigation treatments are not just attributable to the amount of irrigation water as PRD trees maintained higher $\mathrm{g}_{\mathrm{s}}$ levels and better water status than DI trees, although both treatments supplied the same amount of water. In PRD trees, a combination of root-generated ABA signal and unaltered water status was likely responsible for partial stomatal closure and sufficient carbon fixation to support growth. Even when $\mathrm{g}_{\mathrm{s}}$ of PRD trees was more markedly reduced, as shown in Trial 2, vegetative growth was preferentially reduced over fruit growth. This could be due to several reasons. First, the irrigation treatment was imposed after most of fruit cell division was completed, and cell number is known to be the primary factor determining final fruit size. Second, PRD trees were able to somewhat reduce crop load and avoid direct fruit sink competition. Third, fruits generally act as stronger sinks than shoot apices (Wardlaw 1990), and they may also represent strong sinks for water during cell expansion when sugar accumulation and water loss by skin transpiration lower fruit water potential. Similarly, late-season water deficit imposed by controlled irrigation did not influence Braeburn apple fruit size (Kilili et al. 1996; Mills et al. 1996).

Conversely, in DI trees drastic $\mathrm{g}_{\mathrm{s}}$ reductions were probably associated with the coupled action of hormonal and hydraulic signals, and their timing during fruit development determined a negative effect on carbon assimilation and cell turgor, resulting in reduced vegetative and fruit growth.

This study shows that water savings obtained solely by reducing irrigation volumes (DI treatment) do not lead to marketable yields and fruit quality comparable with those obtained under conventional or PRD irrigations, thus proving that PRD outcomes are coupled to the way water is applied and not just to the amount of irrigation water. Our observations also indicate that, under our soil and climate conditions, PRD irrigation does not lead to consistent reductions in shoot growth or significant improvements in fruit quality; therefore, in apple, differently from regulated deficit irrigation strategies, PRD should be regarded as an irrigation technique to increase water-use efficiency rather than to contain excessive vegetative growth. Moreover, our observations indicate that rootstock vigour does not influence the response of Pink Lady apple to PRD irrigation.

Different, less detailed experimental approaches comprising several seasons of observations will be needed to reveal possible cumulative effects of PRD irrigation on the balance between vegetative and reproductive growth and, ultimately, define the real potential for commercial application of this technique. The final evaluation and possible application of PRD for apple cultivation must also carefully consider the economic and environmental benefits deriving from water savings and possible management cost reductions (i.e. less pruning, thinning, etc.), which may strongly depend on the type of cultivar, environment, and irrigation system.

\section{Acknowledgments}

This research was financially supported by the Intramural Scientific Research Fundings of the University of Palermo (ex quota 60\%) for year 2004-05. Sincere thanks go to the group of graduate and undergraduate students for their great help in the field and laboratory.

\section{References}

Atkinson CJ, Policarpo M, Webster AD, Kuden AM (1999) Drought tolerance of apple rootstocks: production and partitioning of dry matter. Plant and Soil 206, 223-235. doi: 10.1023/A:1004415817237

Caspari HW, Behboudian MH, Chalmers DJ (1994) Water use, growth, and fruit yield of 'Hosui' Asian pears under deficit irrigation. Journal of the American Society for Horticultural Science 119, 383-388.

Caspari HW, Einhorn TC, Leib BG, Redulla CA, Andrews PK, Lombardini L, Auvil T, McFerson JR (2004a) Progress in the development of partial rootzone drying of apple trees. Acta Horticulturae 664, 125-132.

Caspari HW, Neal S, Alspach P (2004b) Partial rootzone drying. A new deficit irrigation strategy for apple? Acta Horticulturae 646, 93-100.

Chalmers DJ (1989) A physiological examination of regulated deficit irrigation. New Zealand Agricultural Science 23, 44-48.

Chalmers DJ, Mitchell PD, van Heek LAG (1981) Control of peach tree growth and productivity by regulated water supply, tree density, and summer pruning. Journal of the American Society for Horticultural Science 106, 307-312.

De Souza CR, Maroco JP, Dos Santos TP, Rodrigues ML, Lopes CM, Pereira JS, Chaves MM (2003) Partial rootzone drying, regulation of stomatal aperture and carbon assimilation in field-grown grapevines (Vitis vinifera cv. Moscatel). Functional Plant Biology 30, 653-662. doi: 10.1071/FP02115

Dry PR, Loveys BR (1998) Factors influencing grapevine vigour and the potential for control with partial rootzone drying. Australian Journal of Grape and Wine Research 4, 140-148. doi: 10.1111/j.1755-0238.1998. tb00143.x

Dry PR, Loveys BR (1999) Grapevine shoot growth and stomatal conductance are reduced when part of the root system is dried. Vitis 38, 151-154.

Dry PR, Loveys BR, Botting DG, Düring H (1996) Effects of partial root-zone drying on grapevine vigour, yield, composition of fruit and use of water. In 'Proceedings of the 9th Australian Wine Industry Technical Conference'. pp. 128-131.

Dry PR, Loveys BR, Düring H (2000) Partial drying of the rootzone of grape. I. Transient changes in shoot growth and gas exchange. Vitis 39, 3-7.

Ebel RC, Proebsting EL, Evans RG (1995) Deficit irrigation to control vegetative growth in apple and monitoring fruit growth to schedule irrigation. HortScience 30, 1229-1232.

Ebel RC, Proebsting EL, Patterson ME (1993) Regulated deficit irrigation may alter apple maturity, quality, and storage life. HortScience 28, 141-143.

Einhorn T, Caspari HW (2004) Partial rootzone drying and deficit irrigation of 'Gala' apples in a semi-arid climate. Acta Horticulturae 664, 197-204.

Forshey CG, Weires RW, Stanley BH, Seem RC (1983) Dry weight partitioning of 'McIntosh' apple trees. Journal of the American Society for Horticultural Science 108, 149-154.

Goldhamer DA (1997) Regulated deficit irrigation for California canning olives. Acta Horticulturae 474, 369-372.

Gowing DJG, Davies WJ, Jones HG (1990) A positive root-sourced signal as an indicator of soil drying in apple, Malus $\times$ domestica Borkh. Journal of Experimental Botany 41, 1535-1540. doi: 10.1093/jxb/41.12.1535 
Grant OM, Stoll M, Jones HG (2004) Partial rootzone drying does not affect fruit yield of raspberries. Journal of Horticultural Science \& Biotechnology 79, 125-130.

Higgs KH, Jones HG (1991) Water relations and cropping of apple cultivars on a dwarfing rootstock in response to imposed drought. Journal of Horticultural Science \& Biotechnology 66, 367-379.

Hsiao TC (1973) Plant responses to water stress. Annual Review of Plant Physiology 24, 519-570. doi: 10.1146/annurev.pp.24.060173.002511

Kilili AW, Behboudian M, Mills T (1996) Water relations, photosynthesis, growth, and yield of 'Braeburn' apples under reduced irrigation applied at different stages of the growing season. Gartenbauwissenschaft 61, 267-273.

Lampinen BD, Shackel KA, Southwick SM, Olson B, Yeager JT, Goldhamer D (1995) Sensitivity of yield and fruit quality of French prune to water deprivation at different fruit growth stages. Journal of the American Society for Horticultural Science 120, 139-147.

Landsberg JJ, Jones HG (1981) Apple orchards. In 'Water deficits and plant growth'. Vol 6. (Ed. TT Kozlowski) pp. 419-469. (Academic Press: New York)

Leib BG, Caspari HW, Redulla CA, Andrews PK, Jabro JJ (2006) Partial rootzone drying and deficit irrigation of 'Fuji' apples in a semi-arid climate. Irrigation Science 24, 85-99. doi: 10.1007/s00271-005-0013-9

Lo Bianco R, Policarpo M, Scariano L (2003) Effects of rootstock vigour and in-row spacing on stem and root growth, conformation and dry-matter distribution of young apple trees. Journal of Horticultural Science \& Biotechnology 78, 828-836.

Lombardini L, Caspari HW, Elfving DC, Auvil TD, McFerson JR (2004) Gas exchange and water relations in 'Fuji' apple trees grown under deficit irrigation. Acta Horticulturae 636, 43-50.

Lötter J de V, Beukes DJ, Weber HW (1985) Growth and quality of apples as affected by different irrigation treatments. Journal of Horticultural Science 60, 181-192.

Mills TM, Behboudian MH, Clothier BE (1996) Water relations, growth, and the composition of 'Braeburn' apple fruit under deficit irrigation. Journal of the American Society for Horticultural Science 121, 286-291.

Mitchell PD, Jerie PH, Chalmers DJ (1984) The effects of regulated water deficits on pear tree growth, flowering, fruit growth, and yield. Journal of the American Society for Horticultural Science 109, 604-606.

Mitchell PD, van den Ende B, Jerie PH, Chalmers DJ (1989) Responses of 'Bartlett' pear to withholding irrigation, regulated deficit irrigation, and tree spacing. Journal of the American Society for Horticultural Science 114, 15-19.
Mpelasoka BS, Behboudian MH, Green SR (2001) Water use, yield and fruit quality of lysimeter-grown apple trees, responses to deficit irrigation and to crop load. Irrigation Science 20, 107-113. doi: 10.1007/ s002710100041

Naor A (2004) The interactions of soil- and stem-water potentials with crop level, fruit size and stomatal conductance of field-grown 'Black Amber' Japanese plum. Journal of Horticultural Science \& Biotechnology 79, 273-280.

O'Connell MG, Goodwin I (2007) Responses of 'Pink Lady' apple to deficit irrigation and partial rootzone drying: physiology, growth, yield, and fruit quality. Australian Journal of Agricultural Research 58, 1068-1076. doi: 10.1071/AR07033

Parker WC, Pallardy SG (1985) Genotypic variation in tissue water relations of leaves and roots of black walnut (Juglans nigra) seedlings. Physiologia Plantarum 64, 105-110. doi: 10.1111/j.1399-3054.1985.tb01219.x

Santos TPD, Lopes CM, Rodrigues ML, Souza CRD, Maroco JP, Pereira JS, Silva JR, Chaves MM (2003) Partial rootzone drying, effects on growth and fruit quality of field-grown grapevines (Vitis vinifera). Functional Plant Biology 30, 663-671. doi: 10.1071/FP02180

Shackel KA, Lampinen B, Southwick S, Olson W, Sibbett S, Kruger W, Jager J, Goldhamer D (2000) Deficit irrigation: maintaining productivity with less water. HortScience 35, 1063-1066.

Stutte GW, Baugher TA, Walter SP, Leach DW (1994) Rootstock and training system affect dry-matter and carbohydrate distribution in 'Golden Delicious' apple trees. Journal of the American Society for Horticultural Science 119, 492-497.

van Hooijdonk BM, Dorji K, Behboudian MH (2004) Responses of 'Pacific Rose'TM apple to partial rootzone drying and to deficit irrigation. European Journal of Horticultural Science 69, 104-110.

Wahbi S, Wakrim R, Aganchich B, Tahi H, Serraj R (2005) Effects of partial rootzone drying (PRD) on adult olive tree (Olea europaea) in field conditions under arid climate I. Physiological and agronomic responses. Agriculture, Ecosystems \& Environment 106, 289-301. doi: $10.1016 /$ j.agee.2004.10.015

Wardlaw IF (1990) The control of carbon partitioning in plants. New Phytologist 116, 341-381. doi: 10.1111/j.1469-8137.1990.tb00524.x

Zhang JH, Davies WJ (1987) Increased synthesis of ABA in partially dehydrated root tips and ABA transport from roots to leaves. Journal of Experimental Botany 38, 2015-2023. doi: 10.1093/jxb/38.12.2015

Manuscript received 11 December 2007, accepted 2 June 2008 